\title{
Logistics of urban transport infrastructure development as a mechanism for the formation of a comfortable urban environment (in the example of Yaroslavl)
}

\author{
Alexander Kiselev ${ }^{1,2, *}$, Anna Savicheva ${ }^{1}$, Valery Firago ${ }^{1}$, and Sergey Shkiotov ${ }^{1}$ \\ ${ }^{1}$ Yaroslavl State Technical University, Yaroslavl, Russia \\ ${ }^{2}$ Financial University under the Government of the Russian Federation, Yaroslavl branch, Yaroslavl, \\ Russia
}

\begin{abstract}
Currently in Russia the most serious attention is paid to the development of a comfortable urban environment. And there are already specific tasks of the President of the Russian Federation V.V. Putin on increasing the urban environment quality index by 2024 and reducing the number of cities with an unfavorable environment. However, the main problem in the development of a comfortable urban environment today is the state of the urban transport infrastructure and the complexity of its development. This is due to the constant growth in the number of urban residents, with an increase in the number of personal, public transport and freight vehicles necessary to ensure the life of cities, as well as the often poor condition of city roads and dense development of old city blocks, etc. As a result, today we need scientific approaches to solving the problems outlined in the article on the development of urban transport infrastructure, using for this logistics as a tool for effectively solving problems for the development of an urban comfortable environment, including using the experience already available in this area of cities such as Moscow, Kazan, etc. The article outlines topical problems associated with the implementation of the scientific concept of logistics for the development of urban transport infrastructure as a mechanism for solving the problems of forming an urban comfortable environment on the example of Yaroslavl, which are typical for most Russian cities, determined by the weak use of modern technologies in regional management planning.
\end{abstract}

\section{Introduction}

At present, the idea of forming a modern and comfortable urban environment is being actively pursued in Russia. So, for example, the President of the Russian Federation V.V. Putin instructed to improve the quality of the urban environment in Russian cities by 2024. The Decree (National goals and strategic objectives for the development of the Russian Federation for the period up to 2024) provides for an increase in the urban environment quality index by $30 \%$, and a halving in compliance with this index of the number of cities with an unfavorable environment [1]. The most striking example of the implementation of this work is such large cities as Moscow, Kazan, etc. But concerning statistical data, there 
are 1117 cities in Russia today [2]. And the main problem in the development of a comfortable urban environment today is precisely the difficulties in the development of urban transport infrastructure. At the same time, the number of the population in cities is constantly growing. At the same time, the number of personal vehicles in cities is increasing. At the same time, the existing road infrastructure and the state of urban roads negatively affect the operation of urban transport. So, for example, "in 2020, almost 1.6 times more funds (694 million rubles) were spent on the maintenance of the streets of Yaroslavl than allocated in 2021 (431 million rubles). At the same time, both city budget funds and subsidies from the region decreased" [3]. In general, all this makes it difficult for people to move around the city, especially during rush hour in the morning and in the evening, creates inconveniences for people in using transport and makes cities problematic from the standpoint of the comfort of the urban environment. There is no doubt that many programs are being implemented in Russia to develop the transport infrastructure of cities, but, unfortunately, they often do not solve existing problems. Today there are clearly problems associated with the architectural design of urban development, the lack of professionals in construction organizations for the construction of high-quality roads and other modern transport infrastructure of cities, as well as the desire of a number of officials to "save" on the construction of various objects of transport infrastructure in cities and tenders (competitions) for work on its development, which can be won by organizations that are not able to ensure the required quality of performance of the planned work. As a result, today we need scientific approaches to solving the problems outlined in the article on the development of urban transport infrastructure, using logistics for this as a tool for effectively solving problems for the development of an urban comfortable environment. However, developers, road builders and transport infrastructure development officials, municipal government and financial authorities have their own logistics in this process, that is, lobbying, first of all, their own interests, which indicates that the problem requires a scientifically grounded solution.

The relevance of the topic of the article under consideration is determined by the fact that today, in conditions of the constantly increasing traffic load on cities, new approaches to the development of their transport infrastructure are required from the standpoint of the concept of forming a modern comfortable urban environment and the use of modern technologies in regional management planning. At the same time, this approach should be based on the principles of logistics, and logistics itself should be the main mechanism in the development of transport infrastructure as a key factor in the formation of a modern comfortable urban environment.

\section{Materials and methods}

To study the problems of urban transport infrastructure development in order to form a modern urban comfortable environment, a review of scientific publications on the topic under consideration was carried out, analytical and statistical information on the research topic was studied, interviews were conducted with specialists of various levels related to the development of transport infrastructure in the city of Yaroslavl, as one of the developing regional cities of Russia. Research materials on this topic were repeatedly submitted for discussion at various scientific and practical conferences and "round tables" held jointly by researchers, logisticians and practitioners in the field of transport infrastructure development from various organizations. 


\section{Results and discussion}

Currently, many Russian cities are not ready to rebuild their urban transport infrastructure to meet the modern requirements of forming an urban comfortable environment.

Firstly, this is due to the fact that initially the construction of cities was not designed for such a large number of cars that the population and services for the life support of cities have today. For example, statistics show that already 7 years ago, "137 thousand vehicles, including 80 thousand cars, drove around the city of Yaroslavl, one of the regional centers of the central part of Russia. And "there were 226 cars per 1000 inhabitants of the city." According to the traffic police, their number is increasing by 12 percent annually [4]. Consequently, we can assume that today there can be from 480 to 500 cars per 1000 inhabitants of Yaroslavl.

It should be borne in mind that buildings, especially in the historical part of the city, do not allow expanding the carriageway of roads. At the same time, urban development in Soviet times did not provide for such a large capacity of the city's roadways, which is required today, which negatively affects the development of a comfortable urban environment in modern conditions. In addition, the existing approaches to the development of the city's transport infrastructure exacerbate the problems. For example, during these years, the development of courtyards in the city center with new residential and office buildings was actively carried out. As a result, territories where it was possible to make parking for cars disappeared. The Resolution of the Yaroslavl Mayor's Office No. 1777 of December 29, 2017 "On the municipal program" Formation of a modern urban environment for 2018-2024 "states that one of the main problems in the city is the lack of specially equipped parking spaces for vehicles in most courtyards" [5]. At the same time, many residential and administrative buildings were fenced off or the entrance to their courtyards was limited by barriers. As noted by a member of the Yaroslavl branch of the Union of Architects O.A. Mazanov, "they build just any way, violating the urban planning structure of quarters, the scale and nature of the historical environment, violating the historical building line", etc. [6]. We need a comprehensive program for the development of the city's transport infrastructure based on logistics approaches, taking into account the prospect of creating a comfortable urban environment. In other words, all administrative structures of the city must solve the problems of transport infrastructure development in a coordinated and comprehensive manner in the interests of creating a comfortable urban environment. So, for example, the city's development plans today include issues on the organization of road traffic. In particular, we are talking about the creation of dedicated lanes for public transport, the allocation of additional lanes in front of intersections, the introduction of an intelligent traffic management system and the development of parking space, including through the introduction of paid parking in the UNESCO zone [7]. But given the condition of the roads and the poor quality of their repair and construction, these measures will not ensure the expansion of the traffic flow. At the same time, various administrative structures and organizations most often work based on corporate interests. For example, in Yaroslavl, in the city center, there were two parking lots for personal vehicles of residents, which the city administration decided to make paid. As a result, they now stand empty, and all the streets of the city in the city center are filled with cars on both sides of their carriageway. This reduces their throughput and increases the number of congestion and traffic jams for vehicles. In winter, due to problems with snow removal, which is hindered by cars parked to the side of the road, the roadway in some places is reduced so that buses and trolleybuses of the opposite direction cannot pass. Ultimately, traffic jams, especially during rush hour, are becoming common in cities. These problems are typical for most other Russian cities. This problem needs to be solved through the construction of new roads. However, in Yaroslavl, for more than 10 years, they have been talking about the construction of a new 
modern road, following the example of such a road, which is being done in Moscow, allowing to reduce the traffic load on the city center. "The authorities of Yaroslavl have scheduled for years how they will build the largest transport interchange in the city. In early documents it was called Karabulinskaya, in the last published strategy of socio-economic development of Yaroslavl from 2021 to 2030 it is called simply a transport interchange" [8]. But "On May 11, 2021, the mayor of Yaroslavl V. Volkov signed a decree according to which it is possible to build again on the lands reserved for the Karabulinskaya interchange" [9]. At the same time, a second road bridge across the Volga River was additionally built in Yaroslavl. For some time the severity of the problem was reduced, but now there is a need to build a third bridge, given the amount of transport in Yaroslavl. Indeed, back in 2016, at that time, the first deputy mayor of Yaroslavl, S. Yastrebov, argued that with 250 cars per 1000 inhabitants, "a bridge must be built, otherwise traffic in Yaroslavl will stop" [10]. However, there is still no final decision on the place of construction of the bridge in the next 10 years [6] . In other words, the development of transport infrastructure today is still being addressed not in anticipation, but as the problems worsen. And the main reason for this situation, referred to by the city authorities, is the lack of funds for construction. Today this is the most "convenient" excuse for those problems of transport infrastructure development that are not being resolved. And in such conditions, there is no need to talk about the formation of a modern comfortable environment in the city in the near future, although the municipality of Yaroslavl has approved a strategy for the socio-economic development of the city for the period 2021-2030.

Secondly, considering the strategy of socio-economic development of the city for the period 2021-2030 approved by the municipality of Yaroslavl, it can be considered that it often talks about the resolution of existing problems in the long term, but does not take into account future problematic issues in the growth dynamics. As the experts noted, the city's socio-economic development strategy did not include some projects important for the city, including those on which public discussions were held and even their projects were ordered. O.A. Mazanova notes that the program does not say anything about limiting the numerous construction in the historical center, about excluding the vicious practice of small-scale construction of the city. As a result, it is not possible to create equipped parking spaces for personal vehicles of citizens and their cars occupy a significant part of the carriageway of city roads, hindering the movement of others, including public transport. At the same time, in 2013, studies were carried out in Yaroslavl to optimize public transport routes. The money for the research was spent, but the result of the work turned out to be formal and did not lead to real practical results. And now the issues of logistics of public transport are relevant. At the same time, the chief architect of Yaroslavl A. Tsymbalov believes that the organization of regional centers in the largest districts of Yaroslavl will help to solve this problem. The abandonment of the microdistrict type of development and the return to quarter development, with the transfer of the first floors of residential buildings to public institutions and organizations would help, in his opinion, to overcome the functional imbalance in the development of urban areas, with the transfer of the first floors of residential buildings to public institutions and organizations, since the division of the city into sleeping areas and the business part forces many citizens make daily trips to the place of work, which leads to the formation of congestion and traffic jams during peak hours [6]. But how to implement this idea in existing cities, there are still no specific practice-oriented proposals aimed not only at preventing future problems, but even many existing problems in the development of the city's transport infrastructure.

Thirdly, there is a large flow of freight transport through Yaroslavl, including transit, but there is no full-fledged road bypass, and in the near future it will not be. At the same time, given how "upset" Yaroslavl is, the old bypass road actually passes through the city's territory, which creates an additional load on the city's transport infrastructure. And the 
road itself almost every year in the spring requires its repair, which leads to congestion and traffic jams on the road of freight, urban and individual vehicles. The issue of organizing a deep road bypass of the city today is the most acute for the region and requires an urgent solution. Of course, according to the plans such a road will be built, but anyway these are only intentions [11]. At the same time, even the repair of the existing bypass road is going on with difficulty. For example, the YAROSLAVIA State Television and Radio Broadcasting Company, in its program in March 2021, noted that "today the pits are covered with dubious crumbs, and tomorrow the process will be repeated. The southwestern district, practically the face of the city for motorists from all over Russia, is falling apart before our eyes. The speed of movement here is human, $5 \mathrm{~km}$ per hour. And not only because of one thousand and one pits" [12]. At the same time, the repaired bridge had to be repaired anew due to the cracks formed, since "after the construction and installation works, tests and opening of traffic for road transport, structural defects were revealed on its left side. It was necessary to close the traffic again, carry out examinations, take measurements. As a result, the experts came to the conclusion that there was a mistake in the design" [13]. The work was carried out by the AO EKS GC contractor under a contract worth over RUB 490 million. In June 2020, an additional 292 million rubles were allocated to complete the work. In general, about 1 billion rubles were spent on the work on the bridge. It was planned that the bridge will be commissioned in October 2020 [14]. This indicates, in our opinion, that the organization that won the tender for its renovation did not have the necessary professional specialists, hiring cheaper labor from among the migrants. This also applies to the repair of other urban roads. Thus, a situation is created when a lot of money is spent annually on poor-quality repair of transport infrastructure, which will ultimately be more costly than high-quality construction of new transport infrastructure, which ultimately determines the comfort of the urban environment.

Fourth, the development of cities, associated with an increase in their territory and population, requires the improvement of public transport logistics. So, for example, according to the Yaroslavl mayor's office, in 2019 more than 800 units of passenger transport of all types went to the roads of the capital of the Golden Ring [15]. Unfortunately, today we can assert that constant reforms in organizing the work of public transport do not give the result people need. Reforms and optimization of the transport infrastructure of public transport in Yaroslavl are ongoing. But we must remember that it is very important not to overdo it with the level of provision of logistics services, since the rule always works: "Leave well enough alone" In 2013, in Yaroslavl, comprehensive studies were carried out to optimize public transport routes with the involvement of students from Yaroslavl universities. The money was spent, but there was no practical result from the study. After that, a reform was carried out in 2019, when the authorities intend to optimize the route network, transfer all routes without exception to a regulated tariff and revise the type of rolling stock "in terms of availability and capacity" [15]. From July 14, 2021, changes are coming again related to the reform of public transport, which raise many questions among the population. So, for example, residents of the city do not understand why they remove through routes, and introduce new ones that require people to change during their trips, assign new numbers to existing routes, remove minibuses, etc. [16]. And all this is linked to the formation of a modern comfortable environment.

Fifth, it is the scientifically grounded principles of logistics that should lie in the reform of the transport system of cities. But when planning the reform of the transport infrastructure of the city of Yaroslavl, all the organizations involved solve only their own tasks, which increases the financial costs of various activities. So, for example, the fact that the regional government intervened in the implementation of the developed reform and the scheme for its implementation was altered, raised questions. And they did it, according to 
experts, badly, since the transport reform turned out to be unreasonably costly for the budget [16]. The head of the city passenger transport department of the Yaroslavl mayor's office S. Volkanevsky believes that "further formation of the route network should be carried out taking into account the transition to long-term municipal contracts based on payment for the transport work of carriers" [16]. At the same time, the solution of the problems of development of transport infrastructure by "separate", one-off measures with the appearance of work does not provide the required result. So, for example, the expansion of individual sections of city roads does not solve, but only exacerbates the problems of road infrastructure, since the traffic capacity of roads does not increase, but creates a bottleneck effect, when a lot of traffic jams are formed on the roads in which it stands. including public transport, disrupting the traffic schedule, and, accordingly, difficulties are created for people, increasing the time of their movement around the city. At the same time, even new sections of roads today are often made in such a way that after a while they become unusable or require constant repair, especially in the spring after the snow melts. People often joke bitterly that in spring, along with snow, asphalt leaves the roads. So, for example, in April 2021, the media noted that "in Yaroslavl, the asphalt on Uritskogo Street collapsed. Repair of the roadway worth 53 million rubles. spent here four years ago. The work was carried out by the contracting organization OOO Trassa. The company had to replace the $2.1 \mathrm{~km}$ asphalt pavement, repair sidewalks, replace curbs, install new road signs and apply markings. As a result, the terms of the street repairs were disrupted, and the asphalt pavement began to deteriorate. The local residents and the authorities of Yaroslavl were outraged by the quality of the repairs" [17]. And this is not an isolated case. Unfortunately, such news is given systematically in the media. So, in the fall of 2020, information about the repair of a section of the road near the village Volochkovo near Yaroslavl was reported on the social networks of the federal national project "Safe HighQuality Roads" . The cost of repairs cost 368 million rubles. However, after winter in the spring of 2021, local residents were outraged by the condition of the repaired road. They wrote indignantly on social networks: "A layer of asphalt is like butter on bread. So much for safe and high-quality roads!" [18]. And similar problems today are relevant for most Russian cities. We must not forget that the increase in the number of cars in the city is due to the fact that the amount of payment of the transport tax is increasing, and, consequently, the funds that should be used to improve the transport infrastructure of the city. This suggests that it is impossible to explain the problems of poor development of the transport infrastructure of cities only by the lack of funding for the planned work. And now there are many complaints from the population of Yaroslavl about the inconvenience of traffic. As a result, in order to solve these problems, the governor of the Yaroslavl region was forced to intervene so that the problems of carrying out the transport reform were resolved.

Thus, we can assume that today we need not just separate solutions in resolving the identified problems of individual leaders of regional and local authorities. Their solution should be based on the scientific foundations of logistics, first of all, on the development of urban transport infrastructure, since it characterizes the urban environment to a greater extent as comfortable or not comfortable. And it is precisely the logistics of urban transport infrastructure development that should act as a mechanism for the formation of a comfortable urban environment in Russian cities in modern conditions.

\section{Conclusions}

Today, in many Russian cities, the task of creating a comfortable urban environment is being solved, taking into account the development of society and the needs of people. The most problematic in solving this problem is the creation of an appropriate transport infrastructure in cities, which should be developed on scientific principles of logistics, 
comprehensively and in close interaction of all structures and organizations of the city involved in its development. At the same time, all possible risks associated with the development of the city's transport infrastructure should be taken into account and thought out, including both objective ones, due to the need for effective use of the allocated financial resources, and subjective ones, determined by the human factor [21].

In the example of Yaroslavl, the article highlights the main problems of forming a comfortable urban environment based on the development of the city's transport infrastructure. At the same time, it is substantiated that it is the development of transport infrastructure that is a key factor in the formation of a comfortable environment in Russian cities. And individual one-time, albeit large projects for the expansion of individual road sections, road construction without scientific approaches from the standpoint of logistics, and not a formal possibility or impossibility. There is not doubt that the basis for decisions on the development of urban transport infrastructure should be predicted indicators for the development of the urban environment as a comfortable urban environment from the standpoint of strategic management and strategic planning of this work [22]. Accordingly, the measures for the development of the transport infrastructure of cities today should be ahead of the possibility of the onset of problem and risk situations.

But, today problems in this area often begin to be resolved only after a critical situation has been created, when further ignoring it leads to social tension among city residents. At the same time, they are still trying to implement their solution by holding separate measures, justifying this by a lack of funding.

At the same time, statistics show that the use of allocated funds for the development of transport infrastructure is very often ineffective and does not bring the desired result. At the same time, the measures taken do not ensure proactive development of the transport structure.

Thus, the time has come to address the issues of forming a comfortable urban infrastructure from a scientific standpoint, taking into account the trends of its development, and using modern technologies in regional management planning. At the same time, in modern conditions, the main problems of creating a comfortable environment are directly related to the development of urban transport infrastructure. According to that, the logistics of urban transport infrastructure development as a scientific concept can be considered a mechanism for its formation, taking into account the social development of Russian cities, which requires the use of modern technologies in regional management planning.

\section{References}

1. Putin instructed to radically improve the comfort of the urban environment by 2024, https://tass.ru

2. List of cities in Russia by population, https://chislennost.com

3. In Yaroslavl in 2021, the cost of road maintenance has been reduced, https://regnum.ru

4. In Yaroslavl and the region, there are already 226 cars per 1000 inhabitants, https://www.yarcom.ru

5. Resolution of the Mayor's Office of Yaroslavl No. 1777 of December 29, 2017 (The municipal program: Formation of a modern urban environment for 2018-2024), https://docs.cntd.ru

6. A third bridge across the Volga and a new ring road will be built in Yaroslavl, https://www.kommersant.ru 
7. A third bridge across the Volga and a new ring road will be built in Yaroslavl, https://76.ru

8. The Mayor's Office of Yaroslavl drew up plans for the construction of the Karabulinskaya junction, https://76.ru

9. The refusal of the Karabulinskaya junction in Yaroslavl will be checked by the Prosecutor General's Office, https://r76.su

10. How many cars are there in Yaroslavl? https://yarportal.ru

11. Around Yaroslavl they plan to build a new bypass road, https://r76.su

12. In Yaroslavl, the South-Western ring road is falling apart, https://vesti-yaroslavl.ru

13. Repair of the Dobryninsky bridge in Yaroslavl will be completed in 2021, https://www.kommersant.ru

14. Half-bridge with a crack, https://www.kommersant.ru

15. Everyone is under one rate, https://rg.ru

16. There will be no transitional period: how will transport in Yaroslavl change after the reform, https://76.ru

17. In Yaroslavl, the road to Uritsky collapsed. The repair cost 53 million rubles, https://ufocar.ru

18. "A layer of asphalt is like butter on bread": a road for 368 million is falling apart near Yaroslavl, https://progorod76.ru

19. A. A. Kiselev, Fundamentals of strategic management and the essence of strategic planning in organizations (Direct-Media, Berlin, 2020), 343

20. A. Kiselev, M. Ugryumova, A. Strausova and M. Majorova, The Int. Scientific And Practical Conf. "Ensuring The Stability And Security Of Socio-Economic Systems: Overcoming The Threats Of The Crisis Space" 